\title{
Gross motor development of preschool children: effects of socioeconomic status and maternal education
}

\author{
Cemil Özal $^{1 \oplus,}$ Birgül Bayoğlu² ${ }^{2}$ Sevilay Karahan ${ }^{3}$, Mintaze Kerem Günel $^{1}$, \\ Banu Anlar ${ }^{4}$ \\ ${ }^{1}$ Department of Physiotherapy and Rehabilitation, Hacettepe University Faculty of Health Sciences, Ankara; ${ }^{2}$ Department of Child \\ Development, Bayindır Hospital, Ankara; Departments of ${ }^{3}$ Biostatistics and ${ }^{4}$ Pediatric Neurology, Hacettepe University Faculty of \\ Medicine, Ankara, Turkey.
}

\begin{abstract}
Motor development reflects the general health status of the child and affects other areas of development. It is influenced by biological and family characteristics especially in infancy and early childhood, and by environmental conditions in preschool age. We assessed the effect of several family and environment characteristics on gross motor developmental items included in the Denver-II test on 2,042 healthy children. Increasing maternal age and education were associated with later achievement in several items after age 12 months while socioeconomic status, sex and birth rank did not show a clear effect. Our observations suggest in a relatively homogenous urban population, few external factors affect gross motor development in preschool children.
\end{abstract}

Key words: gross motor development, children, maternal, socioeconomic factors.

Surveillance of psychomotor development is an important part of pediatric care especially in the first years of childhood. Early detection of possible delays allows early intervention and, in certain etiological groups, medical treatment. ${ }^{1}$ Gross motor development is frequently affected by the child's general health status such as vitamin and mineral deficiency or chronic systemic disorders. Therefore, gross motor delays may constitute a warning sign for medical conditions. On the other hand, primary developmental problems such as those in motor control and perception affect up to $6 \%$ of schoolage children and their early detection can lead to appropriate educational interventions. ${ }^{2}$ Physicians should therefore possess knowledge about factors affecting motor development, the degree and nature of their effects, and the range and limits of normal variation.

Cemil Özal

cemilozal@hotmail.com

Received: 26th January 2018; revised: 5th January 2019; accepted: 9th January 2019
Development is ideally evaluated using standardized tests which in clinical practice consist of parental questionnaires or screening tests. ${ }^{1}$

Developmental screening tests are standardized tools used for identifying children who need more detailed evaluation and if used appropriately are useful. ${ }^{3}$ Since screening is used for identifying children who will receive the benefits of more professional evaluation or treatment, it is recommended that all children be screened for developmental delays. ${ }^{3}$ There are many developmental screening tools which are based on achieving developmental milestones at specific chronological ages. Denver Developmental Screening Test II (DDSTII) is one of the examples for such formal tools. ${ }^{4}$ In order to differentiate between abnormal children and normal children who have slower rates of achieving developmental skills, these developmental screening tools must be reliable and valid, as well as have acceptable sensitivity and specificity. ${ }^{5}$ 
DDST-II is a formal developmental screening tool that assesses children from birth to 6 years of age. DDST-II is a brief and validated screening tool; although there is doubt about its limited specificity $(43 \%)$ and risks of over referral, it has high rate of sensitivity $(83 \%)$ and identifies children with developmental delays. ${ }^{5-6}$

Developmental assessment should take into account the family and environmental factors that strongly affect the results. ${ }^{7-9}$ In this study we examined developmental screening test results in pediatric outpatient settings and the role of possible variables such as maternal age, education and socioeconomic status as factors affecting gross motor development of urban children.

\section{Material and Methods}

\section{Participants}

Healthy children were sought in community health centers, well-baby clinics, private practices, kindergartens and day care centers in 7 metropolitan districts of Ankara during the collection of normative data for the standardization of the Denver II Developmental Test for Turkey (Denver II -Turkey) between 2011 and 2012.

Exclusion criteria were, 1) prematurity $<37$ weeks gestational age, 2) birth weight under 2,500 g, 3) past history of hospitalization, 4) congenital malformation, 5) any illness during testing time. Only one child per family was tested in order to avoid over-representation of any particular factor. Total 2,042 children, 1,041 girls (51\%) and 1001 boys (49\%), aged 0 to 72 (minimum 3, maximum 72, mean 24.8 \pm 20.4 ) months were included. Each participants' parents signed informed consent. Ethical approval was obtained from Faculty of Medicine ethics committee (46954233-604.02).

Four levels of maternal education were defined, illiterate (n: $41,2 \%)$, schooling of $\leq 8$ years (n: $734,35.9 \%$ ), $8-12$ years (n: $778,38.1 \%$ ), or $\geq 12$ years (n: $489,23.9 \%$ ). Birth rank of the child was compared in three groups: first child (n: 1035, $48.8 \%$ ), second child (n: $737,34.8 \%$ ), and third child or above (n: 270, 16.4\%) in the family.

The socioeconomic status of the family was recorded on a questionnaire designed by a sociologist based on parents' occupation, years of schooling, household income, residential area, participation to cultural, leisure and sportive activities. Principal component analysis was applied and three different socioeconomic groups were formed according to the standards of the Turkish Institute of Statistics: low (n: 760, 37.2\%; at least 0.5 standard deviation [SD] below the mean), medium (n: 796, 39.0\%; mean $\pm 0.5 \mathrm{SD}$ ), and high (n: 486, 23.8\%; at least $0.5 \mathrm{SD}$ higher than the mean) socioeconomic levels. ${ }^{10,11}$

\section{Assessment tool}

The Denver II test standardized for Turkey comprises 134 items from age 0 to 78 months, of which 37 are in the gross motor domain. Children's "pass" or "fail" status were recorded for each item, and the mean age each item was passed was calculated. Testing was done in a quiet room in the presence of the tester, the child, and the primary caregiver, usually the mother, using standard test material.

\section{Inter and intra-rater reliability}

The test was administered by 4 students of the departments of psychology or child development in Hacettepe University. They were all trained in the use of Denver II by attending a one-week course and had been using the test for at least 3 months prior to the initiation of the study. Examiners reached at least $90 \%$ inter- and intra-rater concordance at the beginning of the project and reliability was re-checked two months later. Data collection was completed in 3 months.

\section{Statistical analysis}

The mean age children passed each gross motor item, standard deviation of the mean, minimum and maximum values were calculated. The results of tests were expressed as the number 
of observations $(\mathrm{n})$, mean \pm standard deviation (SD). Homogeneity (Levene's) and normality (Shapiro Wilk) tests were used to choose statistical methods. Groups with normal distribution and homogeneous variances were assessed by using Pearson's correlation coefficient. As parametric test assumptions were not available for some variables, these were assessed by using Spearman rho correlation coefficient. All statistical analyses were performed with the SPSS software (SPSS ver. 17.0; SPSS Inc., Chicago IL, USA), and $\mathrm{p}<0.05$ was considered statistically significant.

\section{Results}

Mean ages when gross motor milestones were accomplished are shown in relation with socioeconomic level, maternal education and maternal age in Tables I, II and III.

There was no significant difference between boys and girls in any items. Birth order did not affect any gross motor item except 'kick ball forward' (p: 0.049), which was later in the first child. Children of high socioeconomic level (HSL) accomplished items 'lift head', 'bear weight on legs', 'stand 10 seconds', 'walk independently', 'stoop and recover' and 'heel to toe walk' at significantly younger ages than the other two groups (Table I). On the other hand, 'stand holding on', 'walk holding onto furniture', 'stand 2 seconds', 'ride tricycle' and 'broad jump' were accomplished significantly later by children of HSL $(\mathrm{p}<0.001)$.

Between maternal education groups, 'stand 10 seconds' (p: 0.018) was significantly earlier in children of less educated mothers compared to university graduate mothers. Items 'broad jump', 'catch bounced ball' and 'run' were performed later by children of mothers with $\geq 12$ years education compared to other groups ( $\mathrm{p}$ : 0.004; p: 0.03; $p<0.001$, respectively). 'Balance each foot 1 second' (p: 0.037) and 'balance each foot 7 seconds' (p: 0.011) items were earlier in high educated group than other groups (Table II).
According to maternal age, 'run' ( $\mathrm{p}<0.01)$, 'jump up' (p: 0.003), 'ride tricycle' (p: 0.001), 'balance each foot 2 seconds' (p: 0.002), 'broad jump' ( $p<0.01)$, 'catch bounced ball' ( $p: 0.011$ ) and 'balance each foot 9 seconds' (p: 0.021) items were related with maternal age and as mother's age increased, children tended to be later in these items (Table III).

\section{Discussion}

Motor development influences the child's social adjustment, learning, and school performance, and motor delays may be a sign of a global developmental problem where early intervention improves outcome. ${ }^{12}$ Knowledge about factors affecting development allows the clinician to identify adverse practices and environments. ${ }^{13}$

In the young child, the environment mainly consists of the family. Parental, especially maternal education and mother-child interaction affect the amount of cognitive and emotional stimulation given to the child, which is strongly related to motor development. In a study on 6 months-old infants from Sweden, older maternal age and having older siblings, together with maternal depression and feelings of loneliness, affected several developmental areas. ${ }^{14}$ Our results showed older maternal age associated with later motor development in the toddler age group.

Income is an important indicator of the family's assets and opportunities offered by the home environment. Freitas et al. ${ }^{14}$ observed positive correlation between the dimensions of the home (daily activities and play materials) and global motor performance. Adverse environmental factors are more likely to be found in socioeconomically disadvantaged communities. Although our study was done in central-metropolitan areas of Ankara city where families living below poverty line are rare, the socioeconomic structure of the city varies among different districts, mostly due to the effect of rapid urbanization. Cultural 
Table I. Mean age (months) of gross motor skills according to socioeconomic level.

\begin{tabular}{|c|c|c|c|c|c|c|c|}
\hline \multirow[b]{3}{*}{ Test items } & \multicolumn{6}{|c|}{ Socioeconomic levels } & \multirow[b]{3}{*}{$\mathrm{p}$ value } \\
\hline & \multicolumn{2}{|c|}{ Low } & \multicolumn{2}{|c|}{ Medium } & \multicolumn{2}{|c|}{ High } & \\
\hline & $\mathrm{n}$ & Mean \pm SD & $\mathrm{n}$ & Mean \pm SD & $\mathrm{n}$ & Mean \pm SD & \\
\hline Equal movements & 1 & 0.07 & 1 & 0.03 & 4 & $0.12 \pm 0.09$ & $>0.05$ \\
\hline Lift head & 39 & $1.82 \pm 0.46$ & 18 & $1.81 \pm 0.39$ & 23 & $1.33 \pm 0.64$ & 0.015 \\
\hline Head up 45 degrees & 73 & $3.43 \pm 0.90$ & 58 & $3.56 \pm 0.87$ & 44 & $3.74 \pm 0.77$ & $>0.05$ \\
\hline Sit head steady & 71 & $3.56 \pm 1.01$ & 75 & $3.46 \pm 0.96$ & 55 & $3.81 \pm 0.87$ & $>0.05$ \\
\hline Head up 90 degrees & 49 & $4.31 \pm 0.64$ & 37 & $4.34 \pm 0.85$ & 35 & $4.61 \pm 0.65$ & $>0.05$ \\
\hline Chest up with arm support & 42 & $5.29 \pm 0.97$ & 47 & $5.03 \pm 1.05$ & 39 & $5.04 \pm 0.87$ & $>0.05$ \\
\hline Sit no support & - & - & 6 & 7.57 & 1 & 7.5 & $>0.05$ \\
\hline Stand holding on & 38 & $9.19 \pm 0.38$ & 41 & $9.09 \pm 0.76$ & 9 & $9.31 \pm 0.74$ & $<0.001^{\mathrm{a}}$ \\
\hline Get to sitting & 33 & $9.22 \pm 0.37$ & 37 & $9.26 \pm 0.59$ & 8 & $9.65 \pm 0.39$ & $>0.05$ \\
\hline Weight bearing on legs & 94 & $7.90 \pm 1.44$ & 110 & $7.71 \pm 1.40$ & 68 & $7.01 \pm 1.23$ & $<0.001^{\mathrm{a}}$ \\
\hline Pull to stand & 37 & $9.39 \pm 0.58$ & 30 & $9.58 \pm 0.77$ & 20 & $10.39 \pm 0.50$ & $>0.05$ \\
\hline Stand 2 seconds & 36 & $9.47 \pm 0.71$ & 36 & $9.81 \pm 0.91$ & 28 & $10.71 \pm 0.53$ & $<0.001^{\mathrm{a}}$ \\
\hline Walk holding onto furniture & 32 & $9.76 \pm 0.90$ & 28 & $10.28 \pm 0.87$ & 33 & $10.97 \pm 0.61$ & $<0.001^{\mathrm{a}}$ \\
\hline Stand 10 seconds & 31 & $12.58 \pm 1.15$ & 53 & $12.61 \pm 0.85$ & 24 & $11.90 \pm 0.74$ & $<0.001^{\mathrm{a}}$ \\
\hline Walk well & 33 & $13.69 \pm 1.03$ & 49 & $13.16 \pm 1.10$ & 21 & $12.71 \pm 1.35$ & $0.006^{\mathrm{a}}$ \\
\hline Stop and recover & 37 & $13.94 \pm 1.11$ & 48 & $13.34 \pm 1.10$ & 20 & $12.99 \pm 1.43$ & $0.007^{\mathrm{a}}$ \\
\hline Walk backwards & 73 & $15.98 \pm 2.18$ & 110 & $16.11 \pm 2.35$ & 50 & $15.76 \pm 2.76$ & $>0.05$ \\
\hline Kick ball forward & 45 & $14.96 \pm 1.45$ & 60 & $14.68 \pm 1.68$ & 26 & $14.62 \pm 1.82$ & $>0.05$ \\
\hline Walk up steps & 57 & $15.73 \pm 1.56$ & 56 & $16.00 \pm 1.61$ & 18 & $15.78 \pm 1.28$ & $>0.05$ \\
\hline Throw ball overhead & 39 & $17.17 \pm 1.41$ & 67 & $17.14 \pm 1.43$ & 22 & $17.51 \pm 1.38$ & $>0.05$ \\
\hline Runs & 106 & $28.74 \pm 5.44$ & 126 & $29.85 \pm 6.64$ & 67 & $30.56 \pm 6.93$ & $>0.05$ \\
\hline Jump up & 80 & $28.74 \pm 2.54$ & 80 & $28.57 \pm 2.64$ & 33 & $29.53 \pm 2.94$ & $>0.05$ \\
\hline Ride tricycle & 61 & $28.27 \pm 2.77$ & 41 & $28.78 \pm 2.97$ & 25 & $30.33 \pm 1.94$ & $0.009^{\mathrm{a}}$ \\
\hline Balance each foot 1 second & 28 & $31.78 \pm 3.84$ & 29 & $31.73 \pm 3.29$ & 11 & $32.86 \pm 2.61$ & $>0.05$ \\
\hline Balance each foot 2 seconds & 5 & $32.05 \pm 3.91$ & 7 & $34.59 \pm 3.55$ & 5 & $33.92 \pm 2.07$ & $>0.05$ \\
\hline Balance each foot 3 seconds & 14 & $36.61 \pm 2.84$ & 12 & $36.18 \pm 3.80$ & 9 & $36.96 \pm 4.54$ & $>0.05$ \\
\hline Broad jump & 96 & $34.85 \pm 5.05$ & 104 & $35.93 \pm 5.20$ & 71 & $37.04 \pm 5.26$ & 0.041 \\
\hline Balance each foot 4 seconds & 7 & $39.37 \pm 5.00$ & 18 & $40.30 \pm 5.20$ & 8 & $42.24 \pm 5.12$ & $>0.05$ \\
\hline Catch bounced ball & 88 & $38.91 \pm 5.65$ & 88 & $38.96 \pm 5.41$ & 62 & $40.00 \pm 5.25$ & $>0.05$ \\
\hline Balance each foot 5 seconds & 10 & $42.80 \pm 5.44$ & 9 & $42.32 \pm 4.63$ & 12 & $47.21 \pm 4.88$ & $>0.05$ \\
\hline Hops one foot & 50 & $46.11 \pm 5.90$ & 63 & $46.27 \pm 5.33$ & 49 & $47.27 \pm 5.54$ & $>0.05$ \\
\hline Balance each foot 6 seconds & 6 & $44.92 \pm 7.62$ & 11 & $47.12 \pm 5.37$ & 6 & $45.36 \pm 5.63$ & $>0.05$ \\
\hline Balance each foot 7 seconds & 15 & $53.42 \pm 6.40$ & 7 & $48.28 \pm 6.79$ & 6 & $49.36 \pm 3.65$ & $>0.05$ \\
\hline Heel to toe walk & 55 & $59.33 \pm 5.45$ & 79 & $59.92 \pm 5.54$ & 51 & $56.75 \pm 7.04$ & 0.031 \\
\hline Balance each foot 8 seconds & 6 & $55.27 \pm 4.91$ & 11 & $54.91 \pm 7.28$ & 5 & $51.23 \pm 7.83$ & $>0.05$ \\
\hline Balance each foot 9 seconds & 74 & $60.04 \pm 6.80$ & 81 & $61.77 \pm 6.19$ & 34 & $60.14 \pm 7.29$ & $>0.05$ \\
\hline Backward heel to toe walk & 30 & $67.15 \pm 5.40$ & 47 & $67.19 \pm 5.16$ & 28 & $69.31 \pm 5.99$ & $>0.05$ \\
\hline
\end{tabular}

n: count, SD: standard deviation, bold characters indicate $\mathrm{p}<0.05{ }^{a}$ : $\mathrm{p}<0.01$ 
Table II. Mean age (months) gross motor skills according to maternal education groups.

\begin{tabular}{|c|c|c|c|c|c|c|c|c|c|}
\hline \multirow[b]{3}{*}{ Test items } & \multicolumn{8}{|c|}{ Maternal Education (school years) } & \multirow[b]{3}{*}{$p$ value } \\
\hline & \multicolumn{2}{|c|}{ Illiterate } & \multicolumn{4}{|c|}{ Eight years or less $8-12$ years } & \multicolumn{2}{|c|}{ More than 12 years } & \\
\hline & $\mathrm{n}$ & Mean \pm SD & $\mathrm{n}$ & Mean \pm SD & $\mathrm{n}$ & Mean \pm SD & $\mathrm{n}$ & Mean \pm SD & \\
\hline Equal movements & - & - & - & - & 6 & 0.094 & - & - & - \\
\hline Lift head & 6 & $1.82 \pm 0.30$ & 35 & $1.85 \pm 0.36$ & 31 & $1.48 \pm 0.69$ & 8 & $1.57 \pm 0.53$ & $>0.05$ \\
\hline Head up 45 degrees & 5 & $3.91 \pm 0.50$ & 66 & $3.53 \pm 0.96$ & 82 & $3.60 \pm 0.77$ & 22 & $3.36 \pm 0.93$ & $>0.05$ \\
\hline Sit head steady & 6 & $3.36 \pm 1.14$ & 77 & $3.71 \pm 1.01$ & 95 & $3.47 \pm 0.91$ & 24 & $3.69 \pm 0.98$ & $>0.05$ \\
\hline Head up 90 degrees & 3 & $3.88 \pm 0.50$ & 47 & $4.47 \pm 0.73$ & 55 & $4.34 \pm 0.74$ & 16 & $4.54 \pm 0.64$ & $>0.05$ \\
\hline Chest up with arm support & 2 & $6.62 \pm 0.02$ & 46 & $4.97 \pm 0.81$ & 56 & $5.15 \pm 0.97$ & 24 & $5.22 \pm 1.13$ & $>0.05$ \\
\hline Sit without support & - & - & 3 & $7.5 \pm 0.26$ & 3 & $7.63 \pm 0.42$ & 1 & 7.5 & $>0.05$ \\
\hline Stand holding on & 1 & 8.5 & 33 & $9.15 \pm 0.67$ & 35 & $9.17 \pm 0.63$ & 19 & $9.18 \pm 0.56$ & $>0.05$ \\
\hline Pull to sitting & - & - & 30 & $9.23 \pm 0.54$ & 33 & $9.34 \pm 0.51$ & 15 & $9.25 \pm 4.10$ & $>0.05$ \\
\hline Bear weight on legs & 5 & $7.26 \pm 0.78$ & 98 & $7.73 \pm 1.44$ & 122 & $7.48 \pm 1.14$ & 47 & $7.67 \pm 1.53$ & $>0.05$ \\
\hline Pulls to stand & - & - & 37 & $9.65 \pm 0.82$ & 37 & $9.82 \pm 7.02$ & 13 & $9.41 \pm 0.58$ & $>0.05$ \\
\hline Stand 2 seconds & - & - & 38 & $9.83 \pm 0.86$ & 48 & $10.15 \pm 0.94$ & 14 & $9.52 \pm 0.71$ & $>0.05$ \\
\hline Cruising & - & - & 33 & $10.44 \pm 0.90$ & 50 & $10.38 \pm 0.98$ & 10 & $9.86 \pm 0.81$ & $>0.05$ \\
\hline Stand 10 seconds & 3 & $13.33 \pm 0.15$ & 34 & $12.07 \pm 1.17$ & 49 & $12.47 \pm 0.81$ & 20 & $12.84 \pm 0.75$ & 0.018 \\
\hline Walk well & 3 & $13.33 \pm 0.15$ & 28 & $13.00 \pm 1.16$ & 50 & $13.25 \pm 1.12$ & 20 & $13.59 \pm 1.13$ & $>0.05$ \\
\hline Stoop and recover & 3 & $13.33 \pm 0.15$ & 28 & $13.50 \pm 1.33$ & 50 & $13.31 \pm 1.23$ & 22 & $13.96 \pm 1.05$ & $>0.05$ \\
\hline Walk backwards & 7 & $15.96 \pm 2.58$ & 74 & $16.20 \pm 2.47$ & 108 & $15.73 \pm 2.45$ & 43 & $16.39 \pm 1.99$ & $>0.05$ \\
\hline Kick ball forward & 4 & $14.1 \pm 1.54$ & 35 & $15.07 \pm 1.63$ & 65 & $14.70 \pm 1.73$ & 26 & $14.67 \pm 1.40$ & $>0.05$ \\
\hline Walk up steps & 4 & $15.23 \pm 2.24$ & 44 & $15.95 \pm 1.51$ & 60 & $15.90 \pm 1.51$ & 23 & $15.64 \pm 1.63$ & $>0.05$ \\
\hline Throw ball overhead & 2 & $18.25 \pm 0.64$ & 46 & $17.56 \pm 1.40$ & 60 & $16.88 \pm 1.43$ & 20 & $17.32 \pm 1.23$ & $>0.05$ \\
\hline Run & 5 & $26.42 \pm 2.13$ & 95 & $28.20 \pm 5.11$ & 115 & $28.54 \pm 5.97$ & 83 & $32.90 \pm 7.02$ & $<0.001^{\text {a }}$ \\
\hline Jump up & 2 & $31.30 \pm 1.98$ & 67 & $28.91 \pm 2.38$ & 87 & $28.35 \pm 2.64$ & 40 & $29.41 \pm 3.04$ & $>0.05$ \\
\hline Ride tricycle & 1 & 32.7 & 45 & $28.62 \pm 2.51$ & 49 & $28.17 \pm 2.96$ & 31 & $30.06 \pm 2.57$ & 0.08 \\
\hline Balance each foot 1 second & - & - & 20 & $32.77 \pm 3.73$ & 32 & $31.91 \pm 3.80$ & 17 & $31.81 \pm 2.54$ & 0.037 \\
\hline Balance each foot 2 seconds & - & - & 5 & $36.68 \pm 2.31$ & 8 & $32.10 \pm 3.33$ & 3 & $32.20 \pm 0.35$ & $>0.05$ \\
\hline Balance each foot 3 seconds & - & - & 14 & $36.67 \pm 2.80$ & 12 & $35.60 \pm 3.56$ & 9 & $37.63 \pm 4.60$ & $>0.05$ \\
\hline Broad jump & 2 & $33.977 \pm 1.79$ & 85 & $35.40 \pm 5.29$ & 74 & $34.02 \pm 4.90$ & 107 & $37.61 \pm 4.94$ & $0.004^{\mathrm{a}}$ \\
\hline Balance each foot 4 seconds & - & - & 9 & $42.37 \pm 5.72$ & 7 & $41.00 \pm 4.58$ & 19 & $39.86 \pm 5.13$ & $>0.05$ \\
\hline Catch bounced ball & 4 & $40.50 \pm 7.91$ & 80 & $39.80 \pm 5.57$ & 53 & $36.85 \pm 5.60$ & 102 & $39.76 \pm 4.81$ & 0.03 \\
\hline Balance each foot 5 seconds & - & - & 8 & $44.75 \pm 5.58$ & 2 & $41.98 \pm 1.86$ & 22 & $44.10 \pm 5.70$ & $>0.05$ \\
\hline Hops & 3 & $52.07 \pm 2.17$ & 56 & $46.12 \pm 5.29$ & 32 & $46.26 \pm 5.90$ & 69 & $46.67 \pm 5.73$ & $>0.05$ \\
\hline Balance each foot 6 seconds & - & - & 7 & $47.52 \pm 6.19$ & 7 & $47.85 \pm 7.24$ & 10 & $45.56 \pm 6.80$ & $>0.05$ \\
\hline Balance each foot 7 seconds & 1 & 49.63 & 14 & $54.43 \pm 6.26$ & 3 & $58.46 \pm 6.57$ & 12 & $47.41 \pm 3.90$ & 0.011 \\
\hline Heel to toe walk & 3 & $62.70 \pm 3.21$ & 66 & $59.26 \pm 5.96$ & 44 & $59.85 \pm 5.54$ & 74 & $58.00 \pm 6.30$ & $>0.05$ \\
\hline Balance each foot 8 seconds & - & - & 10 & $53.82 \pm 7.90$ & 6 & $52.64 \pm 6.27$ & 6 & $56.29 \pm 5.50$ & $>0.05$ \\
\hline Balance each foot 9 seconds & 4 & $61.97 \pm 7.23$ & 77 & $60.24 \pm 6.92$ & 47 & $61.12 \pm 6.11$ & 61 & $61.58 \pm 6.79$ & $>0.05$ \\
\hline Backward heel to toe walk & 1 & 64.67 & 36 & $67.48 \pm 5.72$ & 26 & $66.56 \pm 5.93$ & 44 & $68.28 \pm 5.36$ & $>0.05$ \\
\hline
\end{tabular}

$\mathrm{n}$ : count, SD: standard deviation, bold characters indicate $\mathrm{p}<0.05$, a: $\mathrm{p}<0.01$ 
Table III. Correlation analysis between developmental milestones and maternal age.

\begin{tabular}{|c|c|c|c|}
\hline Milestones & $\mathrm{N}$ & $\mathrm{P}^{*}$ & $\mathrm{~T}$ \\
\hline Equal movements & 13 & 0.64 & 0.243 \\
\hline Lift head & 86 & 0.34 & -0.107 \\
\hline Head up 45 degrees & 180 & 0.96 & 0.004 \\
\hline Sit head steady & 205 & 0.97 & -0.03 \\
\hline Head up 90 degrees & 124 & 0.23 & -0.110 \\
\hline Chest up with arm support & 130 & 0.98 & -0.002 \\
\hline Sit no support & 25 & 0.66 & -0.205 \\
\hline Stand holding on & 107 & 0.83 & -0.023 \\
\hline Pull to sit & 95 & 0.57 & 0.066 \\
\hline Bear weight on legs & 307 & 0.63 & -0.030 \\
\hline Pull to stand & 105 & 0.44 & 0.084 \\
\hline Stand 2 seconds & 117 & 0.80 & -0.026 \\
\hline Cruise & 109 & 0.49 & 0.073 \\
\hline Stand 10 seconds & 123 & 0.49 & 0.067 \\
\hline Walk well & 117 & 0.69 & 0.040 \\
\hline Stoop and recover & 120 & 0.77 & -0.029 \\
\hline Walk backwards & 247 & 0.17 & 0.090 \\
\hline Kick ball forward & 143 & 0.57 & 0.050 \\
\hline Walk up steps & 140 & 0.13 & 0.134 \\
\hline Throw ball overhead & 134 & 0.11 & 0.143 \\
\hline Run & 304 & $<0.01^{\mathrm{a}}$ & 0.250 \\
\hline Jump up & 202 & $0.003^{\mathrm{a}}$ & 0.208 \\
\hline Ride tricycle & 139 & $0.001^{\mathrm{a}}$ & 0.295 \\
\hline Balance each foot 1 second & 20 & 0.32 & 0.259 \\
\hline Balance each foot 2 seconds & 69 & $0.002^{\mathrm{a}}$ & 0.371 \\
\hline Balance each foot 3 seconds & 35 & 0.93 & 0.015 \\
\hline Broad jump & 278 & $<0.01^{\mathrm{a}}$ & 0.347 \\
\hline Balance each foot 4 seconds & 35 & 0.75 & -0.055 \\
\hline Catch bounced ball & 245 & 0.011 & 0.164 \\
\hline Balance each foot 5 seconds & 32 & 0.35 & 0.172 \\
\hline Hop & 159 & 0.95 & 0.005 \\
\hline Balance each foot 6 seconds & 25 & 0.81 & -0.052 \\
\hline Balance each foot 7 seconds & 30 & 0.64 & 0.090 \\
\hline Heel to toe walk & 187 & 0.68 & 0.031 \\
\hline Balance each foot 8 seconds & 22 & 0.61 & -0.011 \\
\hline Balance each foot 9 seconds & 189 & 0.021 & 0.168 \\
\hline Backward heel to toe & 109 & 0.28 & 0.105 \\
\hline
\end{tabular}

Bold characters indicate $p<0.05$; ${ }^{a}$ : $p<0.01$.

* Pearson correlation analysis 
factors restricting spontaneous play activities may influence gross motor abilities. In nonurban areas low socioeconomic level may be associated with more opportunity for the child's exploration of his/her environment, facilitating motor development. ${ }^{15-16}$

Higher maternal education was associated with earlier development in several studies. ${ }^{13}$ Although in our previous work we found children of more educated mothers developed earlier in gross motor skills ${ }^{17}$, in the current study this difference was observed less prominently and was even observed later in high educated mothers in some items. This difference by years in the same community may reflect differentiations of life styles that more high educated mothers have and welfare conditions in different educational groups. In a study from Greece, maternal educational level and the caregiver being a grandparent or babysitter were found to affect infants' gross motor development assessed by the Alberta Infant Motor Scale, whereas gender, birth order, maternal age, paternal educational level and income were not significant factors. ${ }^{18}$ Koutra et al. $^{18}$ did not find any significant association between gross motor development and maternal education. These findings are not comparable with our study because their age group was up to 18 months, and we observed the main differences associated with maternal education in older children.

Sex was not found to affect motor items in our study, as in others. ${ }^{19}$ Birth rank also lacked any effect in our study. Certain reports emphasized the negative effect of the presence of older siblings. ${ }^{20}$ On the other hand, Berger and Nuzzo $^{19}$ observed having an older sibling provides developmentally more advanced motor development models.

Collaborative systems in motor development include musculoskeletal components, central sensorimotor integrative mechanisms, environment, and motivation. As expected from such a multifactorial function and from heterogeneous populations, our results do not show uniform trends. For instance, increasing educational level of women is expected to increase their employment rates and consequently, socioeconomic status. However, the effect of these two factors is not in the same direction in Turkey. ${ }^{21,22}$ This can be explained by working mother's leaving the child with a nonprofessional caregiver from low educational background, and the child spending more time in closed, indoor spaces with less quality time. This effect is more important in urban areas of developing countries where standard preschool education and day care centers are not widely available. ${ }^{23}$ Providing an enriched and safe environment and experience of motor activities via recreational activities are important for bringing out and enhancing the developmental potentials of children. ${ }^{24}$

Educational or socioeconomic factors appeared to affect certain motor items, although the effect was variable and no specific trend towards one direction was observed. Notably, socioeconomic status appeared effective on functions acquired after age 12 months. Developmental inabilities result from the combination of biological, social and environmental factors. Knowledge of the relationship between motor development and environmental stimulation, and the role of the family to bring out the motor abilities are important for the planning of developmental interventions. Development of motor skills in early childhood can influence future life. Gross motor development affects other developmental domains probably through acquisition of experience and opportunity for exploration. Gross motor items were found to be related to cognitive performance; in particular, subtests of working memory and processing speed in a study using the Ages and Stages Questionnaire, an infant and preschool screening tool based on parental report. ${ }^{25}$

The main limitation of this study is the absence of validation of our screening test results with a diagnostic test. On the other hand, our aim was to examine results applicable in well-baby or primary health care clinics, which provide the earliest opportunity for developmental 
screening. Identifying factors affecting gross motor results in Denver II, the most commonly used screening test in Turkey, helps primary care physicians' approach and correct interpretation of the test, allowing the undertaking of appropriate measures. Our results pertain to Ankara, a city of 5 million inhabitants, and their applicability to smaller towns with different social structure remains to be investigated.

In conclusion, familial and environmental factors are effective on gross motor functions of preschool period. Specific socioeconomic factors seem to influence the infants' motor development. Gender and birth order did not affect gross motor development while maternal education was more effective at 8-16 months and socioeconomic level, in the 10-60 month old period.

\section{REFERENCES}

1. American Academy of Pediatrics, Committee on Children with Disabilities. Developmental surveillance and screening of infants and young children. Pediatrics 2001; 108: 192-196.

2. Caçola P. Movement difficulties affect children's learning: an overview of developmental coordination disorder (DCD). Lear Disabil Multidiscip J 2014; 20 : 98-106.

3. American Academy of Pediatrics Committee on Children with Disabilities. Screening infants and young children for developmental disabilities. Pediatrics 1994; 93: 863-865.

4. Shahshahani S, Vameghi R, Azari N, Sajedi F, Kazemnejad A. Validity and reliability determination of Denver developmental screening test-II in 0-6 year-olds in Tehran. Iran J Pediatr 2010; 20: 313-322.

5. Levine DA. Guiding parents through behavioral issues affecting their child's health: the primary care provider's role. Ethn Dis 2006; 16(2 Suppl 3): S3-21-8.

6. Glasco FP. Are over referrals on developmental screening tests really a problem? Arch Pediatr Adolesc Med 2001; 155: 54-59.

7. Venetsanou F, Kambas A. Environmental factors affecting preschoolers' motor development. Early Childhood Educ J 2010; 37: 319-327.

8. Ramey CT, Ramey SL. Prevention of intellectual disabilities: early interventions to improve cognitive development. Prev Med 1998; 27: 224-232.
9. Smith LB, Thelen E. Development as a dynamic system. Trends Cogn Sci 2003; 7: 343-348.

10. Turkish Statistical Institute: Ankara with Selected Legend. Ankara: Istatistik Kurumu Press, 2013: 8996.

11. Alvik A. Variables predicting low infant developmental scores: maternal age above 30 years is a main predictor. Scand J Public Health 2014; 42: 113-119.

12. Durmazlar N, Ozturk C, Ural B, Karaagaoglou E, Anlar B. Turkish children's performance on Denver II: effect of sex and mother's education. Dev Med Child Neurol 1998; 40: 411-416.

13. Noritz GH, Murphy NA; Neuromotor Screening Expert Panel. Motor delays: early identification and evaluation. Pediatrics 2013; 131: e2016-e2027.

14. Freitas TC, Gabbard C, Caçola P, Montebelo MI, Santos DC. Family socioeconomic status and the provision of motor affordances in the home. Braz J Phys Ther 2013; 17: 319-327.

15. Angulo-Barroso RM, Schapiro L, Liang W, et al Motor development in 9-month-old infants in relation to cultural differences and iron status. Dev Psychobiol 2011; 53: 196-210.

16. Giagazoglou P, Kyparos A. Fotiadou E, Angelopoulou $\mathrm{N}$. The effect of residence area and mother's education on motor development of preschool-aged children in Greece. Early Child Dev Care 2007; 177: 479-492.

17. Syrengelas D, Kalampoki V, Kleisiouni $P$, Konstantinou D, Siahanidou T. Gross motor development in full-term Greek infants assessed by the Alberta Infant Motor Scale: reference values and socioeconomic impact. Early Hum Dev 2014; 90: 353357.

18. Koutra K, Chatzi L, Roumeliotaki T, et al. Socio-demographic determinants of infant neurodevelopment at 18 months of age: motherChild Cohort (Rhea Study) in Crete, Greece. Infant Behav Dev 2012; 35: 48-59.

19. Berger SE, Nuzzo K. Older siblings influence younger siblings' motor development. Infant and child development. Inf Child Dev 2008; 17: 607-615.

20. Kakebeeke TH, Caflisch J, Chaouch A, Rousson V, Largo RH, Jenni OG. Neuromotor development in children. Part 3: motor performance in 3- to 5-yearolds. Dev Med Child Neurol 2013; 55: 248-256.

21. Özer M, Biçerli K. Türkiye'de kadın işgücünün panel veri analizi. Sosyal Bilimler Dergisi 2003; 3: 55-85.

22. Lim HC, Chan T, Yoong T. Standardization and adaptation of the Denver Developmental Screening Test (DDST) and Denver II for use in Singapore children. Singapore Med J 1994; 35: 156-160. 
23. Barros KM, Fragoso AG, Oliveira AL, Cabral-Filho JE, Castro RM. Do environmental influences alter motor abilities acquisition? A comparison among children from day-care centers and private schools. Arq Neuropsiquiatr 2003: 61(2-A) 170-175

24. Piek JP, Dawson L, Smith LM, Gasson N. The role of early fine and gross motor development on later motor and cognitive ability. Hum Mov Sci 2008; 27: 668-681.
25. Krieger N, Williams DR, Moss NE. Measuring social class in US public health research: concepts, methodologies, and guidelines. Annu Rev Public Health 1997; 18: 341-378. 